\title{
Treatment of pediatric Grade II spinal ependymomas: a population-based study
}

\author{
Yimo Lin, BA, ${ }^{1}$ Andrew Jea, MD, ${ }^{1}$ Stephanie C. Melkonian, PhD, ${ }^{2}$ and Sandi Lam, MD, MBA ${ }^{1}$ \\ 'Division of Pediatric Neurosurgery, Texas Children's Hospital, and Department of Neurosurgery, Baylor College of Medicine; \\ and ${ }^{2}$ Department of Cancer Epidemiology, MD Anderson Cancer Center, Houston, Texas
}

\begin{abstract}
OBJECT Grade II spinal cord ependymomas occurring in pediatric patients are exceptionally rare neoplasms. In this paper the authors use a national cancer database to determine patient demographics, treatment patterns, and associated outcomes of this cohort.
\end{abstract}

METHODS The Surveillance Epidemiology and End Results (SEER) database was used to analyze subjects younger than 18 years with histologically confirmed diagnoses of Grade II spinal cord ependymoma from the years 1973 to 2008. Descriptive data on the demographic characteristics of this cohort and the associated treatment patterns are shown. The Kaplan-Meier method was used to estimate overall survival at 1, 2, 5, and 10 years.

RESULTS This cohort comprised 64 pediatric subjects with Grade II spinal ependymoma. The median age was 13 years, nearly half of the patients were male, and most were white (84\%). The median follow-up was 9.2 years. Overall survival at 5 and 10 years was $86 \%$ and $83 \%$, respectively. Gross-total resection was achieved in $57 \%$ of subjects, and radiation therapy was administered to $36 \%$. Radiation therapy was administered to $78 \%$ of subjects after subtotal resection but only to $19 \%$ of patients after gross-total resection; this difference was significant $(p<0.001)$. In a multivariate regression model analyzing sex, age at diagnosis, year of diagnosis, radiotherapy, and extent of resection, female sex was found to be an independent predictor of decreased mortality (HR 0.15 [95\% Cl 0.02-0.94], $p=0.04$ ).

CONCLUSIONS These data show long-term outcomes for pediatric patients with Grade II spinal ependymoma. Radiotherapy was more likely to be administered in cases of subtotal resection than in cases of gross-total resection. Female sex is associated with decreased mortality, while other demographic or treatment modalities are not.

http://thejns.org/doi/abs/10.3171/2014.9.PEDS1473

KEY WORDS spinal cord tumor; ependymoma; pediatric; SEER; children; spinal cord ependymoma; oncology; spine

$\mathrm{P}$ EDIATRIC primary spinal cord neoplasms are rare tumors, with reported estimated incidences of 0.9-2.6 per 100,000 person-years. ${ }^{32,61}$ Among these, astrocytomas are the most common subtype, accounting for an estimated $60 \%-80 \%$ of pediatric spinal cord tumors, with ependymoma making up most of the remaining tumors. ${ }^{29,33,34,39,42,44}$ The reverse pattern is true in adult populations. ${ }^{31,32,42,44}$ The WHO categorizes spinal ependymomas into 3 histological subtypes: Grade I myxopapillary ependymoma; Grade II ependymoma, which includes the cellular, clear cell, tanycytic, and papillary subtypes; and finally Grade III anaplastic ependymoma. ${ }^{43}$

Pediatric Grade II spinal ependymomas are generally intramedullary tumors that occur in the proximal spinal cord. ${ }^{7,42}$ They are slow-growing, indolent tumors with a benign course; in the literature, rates of both overall survival (OS) and progression-free survival (PFS) at 5 years have been reported at $90 \%-100 \% .{ }^{7,42,62}$ Maximal resection is generally agreed to be the cornerstone of treatment for pediatric spinal ependymomas; $; 2,7,3,34,42,47,50$ however, the addition of adjuvant radiation therapy after surgery is the subject of more debate. ${ }^{2,7,8,48}$ While there are many studies on spinal ependymomas in adults, ${ }^{11,12,16-18,21,24,25,38,41,45,51,56,57,61,65}$ there are few papers on these tumors in children, and those that do exist tend to be small, single-institution retrospective studies that are not powered for statistical analysis stratified by tumor grade. ${ }^{2,8,13,22,27,42,47,53}$

The goal of this paper is to use the nationally representative Surveillance Epidemiology and End Results (SEER) database to offer a population-based perspective on pediatric Grade II spinal ependymomas. Specifically, this study provides data on the demographics and treatment patterns in this cohort, as well as the impact of those factors on survival outcomes.

ABBREVIATIONS GTR = gross-total resection; ICD-O-3 = The International Classification of Diseases for Oncology, Third Edition; NOS = not otherwise specified; OS = overall survival; PFS = progression-free survival; SEER = Surveillance Epidemiology and End Results; STR = subtotal resection.

SUBMITTED February 17, 2014. ACCEPTED September 4, 2014.

INCLUDE WHEN CITING Published online December 19, 2014; DOI: 10.3171/2014.9.PEDS1473.

DISCLOSURE The authors report no conflict of interest concerning the materials or methods used in this study or the findings specified in this paper. 


\section{Methods \\ Study Population}

Data for this analysis were obtained from the SEER program (1973-2008) of the National Cancer Institute. This cancer registry includes data from 17 geographic areas in the US and represents approximately $26 \%$ of the US population. For the purposes of the present analysis, cases from Louisiana were not used as suggested by SEER due to noncontinuous reporting of data from the impact of Hurricanes Katrina and Rita in the Gulf Coast region. Site and histology codes of The International Classification of Diseases for Oncology, Third Edition (ICD-O-3) were used to identify cases. Patients younger than 18 years old classified as having histopathologically confirmed ependymoma including cellular, clear cell, tanycytic, and ependymoma not otherwise specified (NOS) (ICD-O-3 Code 9391) and papillary ependymoma (ICD-O-3 Code 9393) in a location classified as spinal cord (C72.0) or cauda equina (C72.1) were included in this study. We included only individuals for whom the ependymoma was their only or first primary tumor. Myxopapillary ependymoma (ICD-O-3 Code 9394) was not included. Subsequent tumors or recurrences were not considered for this analysis. Patients with a survival time of 0 months $(n=3)$ had their survival time changed to 0.5 months to avoid any bias that could result from the exclusion of these subjects. SEER data are publicly available, and exempt status as non-human subjects research was granted by our institutional review board.

\section{Surgical Procedure Data}

In the SEER database, surgical procedure codes were extracted by trained coders to determine the extent of resection. The SEER program has a standardized methodology for coders to look in detail at operative reports, surgeon intraoperative assessment, radiology reports, pathology reports, and medical record notes, and to enter the data according to the FORDS (Facility Oncology Registry Data Standards) manual established by the Commission on Cancer with the American College of Surgeons. We cannot independently confirm the coding assignments. The variable containing surgery codes for the cases diagnosed between 1998 and 2007 was named "RX Summ-Surg Prim Site (1998+)" and was based on the American College of Surgeons Commission on Cancer's Facility Oncology Registry Data Standards. ${ }^{55}$ Field codes for patients diagnosed between 1983 and 1997 were included in the "Site Specific surgery (1983-1997)" variable. Any case diagnosed prior to 1983 was coded using a nonspecific scheme (yes/no/unknown). To create a new variable for analysis that includes cases from all time periods, we recoded the surgical procedures for all years into 6 previously established categories. ${ }^{1}$ Briefly, these categories included: no surgery (pre-1998 codes 00, 01, 03, 04, and 07; for 1998+, code 00); biopsy (pre-1998 code 02; for 1998+, code 20); partial resection (pre-1998 codes 20 and 40; for 1998+, code 40); gross-total resection (GTR) (pre-1998 codes 30, 50, 60; for 1998, code 55); surgery NOS (pre-1998 codes 10 and 90; for 1998+, codes 10 and 90); and surgery status unknown (pre-1998 codes $05,06,09$, and 80; for $1998+$, code 99). ${ }^{39,68}$

\section{Covariates}

Age at diagnosis, sex, race (white, black, American Indian, Asian/Pacific Islander, and other/unknown), Hispanic ethnicity (yes/no), surgery (no surgery/biopsy/partial resection/GTR/surgery not otherwise specified/unknown), radiation therapy (yes/no/unknown), were evaluated in this analysis. For the surgery variable, "no surgery," "biopsy," and "surgery NOS" were collapsed into "no resection," partial resection was "subtotal resection" (STR), and GTR remained as is; unknown status retained its own category but was excluded from most statistical analyses. Detailed patient and treatment-related factors such as chemotherapeutic regimens, radiotherapy technique, radiation dose, and comorbid conditions were unaccounted for in the SEER database and are therefore not evaluated in the present analysis.

\section{Statistical Analysis}

Descriptive analyses were conducted to evaluate the distribution of patient and tumor-related characteristics. The Kaplan-Meier method was used to estimate 10-year, 5-year, 2-year, and 1-year survival; log-rank analyses were conducted to evaluate differences in survival curves. Multivariate Cox proportional hazards models for tumor subsets were conducted to estimate the hazard function using variables identified for analysis based on a priori assumptions of associations with survival. A reverse Kaplan-Meier estimator (using censorship as the event of interest) was used to calculate median follow-up times. ${ }^{15}$ Chi-square tests were used to compare categorical variables; unpaired t-tests were used to compare continuous variables. Statistical significance was defined as $p \leq 0.05$. The statistical analyses were carried out using STATA version 12 (Stata Corp.).

\section{Results}

Overall, this cohort comprised 64 pediatric patients with Grade II spinal ependymoma. The median age was 13 years, nearly half of the patients were male, and most were white (84\%). Among those who underwent surgery, GTR was attained in 57\% and STR was attained in $43 \%$. Only about one-third of the cohort (36\%) received radiation therapy. Adjuvant radiotherapy was statistically significantly more likely to be administered in cases of STR than in cases of GTR ( $p<0.001)$. After STR, $11(79 \%)$ of 14 patients received radiation treatment, while after GTR, only $4(19 \%)$ of 21 patients did. This pattern has not significantly varied over the 3.5 decades examined in the study cohort (Table 1).

Of the 64 subjects, 55 were alive after a median followup of 9.2 years (95\% CI 6.9-12.7 years), and 9 died after a median of 15 months (range 0-96 months). The survival curve is shown in Fig. 1. Overall survival was $94 \%$ at 1 year, $92 \%$ at 2 years, $86 \%$ at 5 years, and $83 \%$ at 10 years. Survival at 10 years was $93 \%$ for females and $74 \%$ for males; this difference was nearly significant by log-rank testing $(\mathrm{p}=0.059)$ (Fig. 2). Overall, chi-square analysis found that females were statistically significantly less likely to die than males $(p=0.045)$. Multivariate regression analyses adjusted for age, year of diagnosis, radiotherapy, and extent of resection found a significant association be- 
TABLE 1. Characteristics in 64 patients with Grade II spinal ependymoma

\begin{tabular}{|c|c|}
\hline Variable & Value $^{*}$ \\
\hline \multicolumn{2}{|l|}{ Sex } \\
\hline Male & $30(46.9)$ \\
\hline Female & $34(53.1)$ \\
\hline \multicolumn{2}{|l|}{ Age at diagnosis in yrs } \\
\hline Mean \pm SD & $11.9 \pm 4.7$ \\
\hline Median & 13 \\
\hline $0-5$ & $9(14.1)$ \\
\hline $6-11$ & $14(21.9)$ \\
\hline $12-17$ & $41(64.1)$ \\
\hline \multicolumn{2}{|l|}{ Race } \\
\hline White & $54(84.4)$ \\
\hline Black & $5(7.8)$ \\
\hline Asian/Pacific Islander & $3(4.7)$ \\
\hline Unknown & $2(3.1)$ \\
\hline \multicolumn{2}{|l|}{ Hispanic Ethnicity } \\
\hline No & $55(85.9)$ \\
\hline Yes & $9(14.1)$ \\
\hline \multicolumn{2}{|l|}{ Period of diagnosis } \\
\hline 1973-2000 & 33 \\
\hline 2001-2008 & 31 \\
\hline \multicolumn{2}{|l|}{ Tumor location } \\
\hline Spinal cord & $62(96.9)$ \\
\hline Cauda equina & $2(3.1)$ \\
\hline \multicolumn{2}{|l|}{ Received radiotherapy } \\
\hline No & $37(57.8)$ \\
\hline Yes & $23(35.9)$ \\
\hline Unknown & $4(6.2)$ \\
\hline \multicolumn{2}{|l|}{ Extent of resection } \\
\hline No resection & $23(35.9)$ \\
\hline STR & $16(25)$ \\
\hline GTR & $21(32.8)$ \\
\hline Unknown & $4(6.2)$ \\
\hline \multicolumn{2}{|l|}{ Follow-up in yrs } \\
\hline Median & 9.2 \\
\hline $95 \% \mathrm{Cl}$ & $6.9-12.7$ \\
\hline \multicolumn{2}{|l|}{ Survival $(95 \% \mathrm{Cl})$} \\
\hline $1 \mathrm{yr}$ & $93.6 \%(83.8-97.5 \%)$ \\
\hline $2 \mathrm{yrs}$ & $92 \%(81.7-96.6 \%)$ \\
\hline 5 yrs & $86 \%(73.7-92.8 \%)$ \\
\hline $10 \mathrm{yrs}$ & $83.2 \%(69.8-91.1 \%)$ \\
\hline
\end{tabular}

* Values are number of patients (\%) unless stated otherwise.

tween female sex and decreased mortality at 10 years (HR 0.15 [95\% CI 0.02-0.94], $\mathrm{p}=0.04$ ). This study found no statistically significant association between OS and age, race/ethnicity, diagnosis year, radiation treatment status, or extent of resection in chi-square, t-test, log-rank, or multivariate regression analyses.

The Kaplan-Meier survival estimate at 10 years for

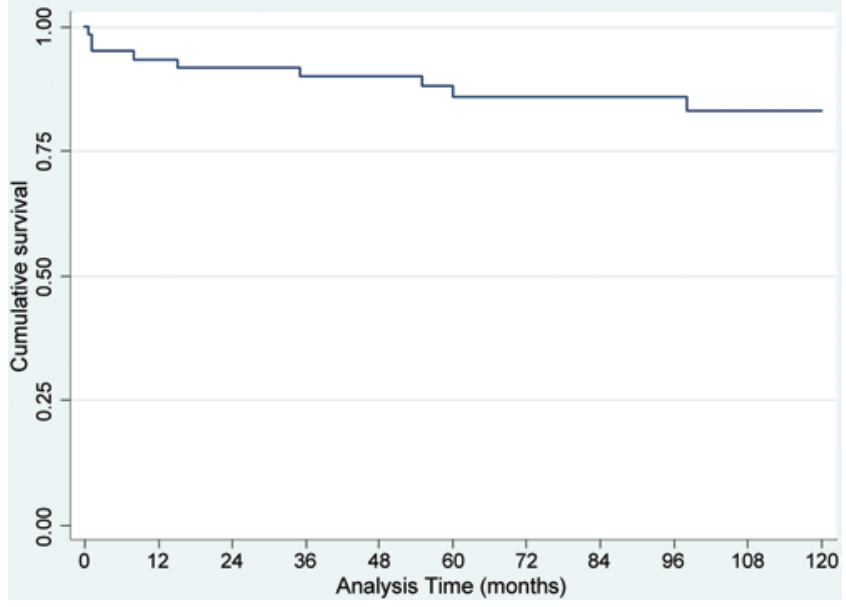

FIG. 1. Kaplan-Meier graph depicting the 10-year survival curve for patients with Grade II ependymoma. Figure is available in color online only.

those who underwent STR was $87.5 \%$ and for those those who underwent GTR it was 93.8\%; this difference was not statistically significant. However, among the patients who did not survive, the survival time for the patient who received a GTR was 55 months, and for the 2 patients who received an STR it was 8 and 15 months. The Kaplan-Meier survival estimate at 10 years for those who underwent radiation therapy was $87.4 \%$, and for those who did not, it was $75.1 \%$; this difference was not statistically significant (Tables 2 and 3).

\section{Discussion}

To our knowledge, this is the largest published series of pediatric Grade II spinal ependymoma cases to date, with 64 subjects overall. The median follow-up was 9.2 years. Overall survival was $86 \%$ at 5 years and $83 \%$ at 10 years. Adjuvant radiation therapy was much more likely to be used in cases of STR than in cases of GTR. Females were significantly more likely to survive than males. Neither extent of resection nor adjuvant radiotherapy significantly affected OS.

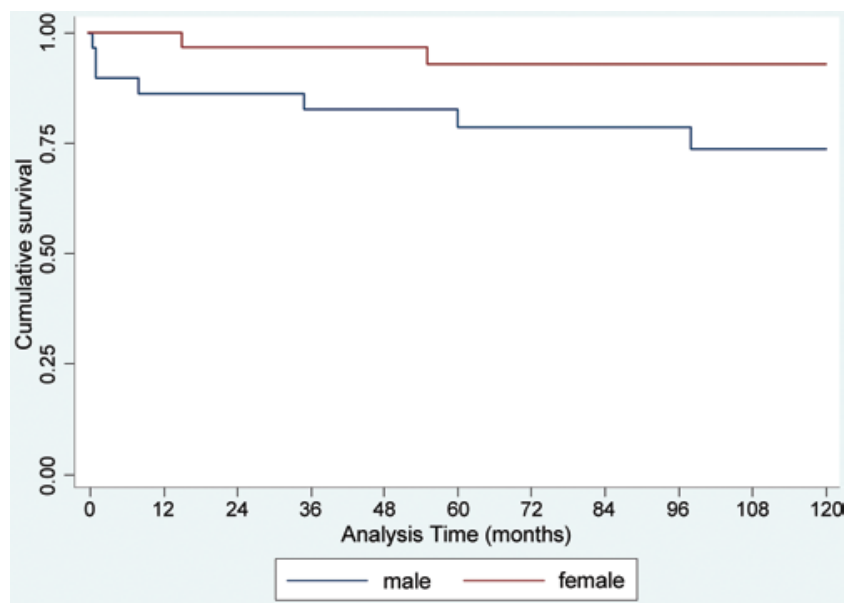

FIG. 2. Kaplan-Meier graph of 10-year survival of pediatric spinal ependymoma patients stratified by sex. Figure is available in color online only. 
TABLE 2. Patient characteristics and survival outcome*

\begin{tabular}{|c|c|c|c|}
\hline Variable & Survived $(n=55)$ & Died $(n=9)$ & $\mathrm{p}$ Value \\
\hline Sex & & & $0.05 \dagger$ \\
\hline Male & 23 & 7 & \\
\hline Female & 32 & 2 & \\
\hline \multicolumn{4}{|l|}{ Age at diagnosis in yrs } \\
\hline Mean \pm SD & $11.8 \pm 4.8$ & $12.3 \pm 4.3$ & 0.75 \\
\hline Median & 13 & 13 & \\
\hline 10th-90th percentile & $3-17$ & $4-17$ & \\
\hline $0-5$ & 8 & 1 & 0.66 \\
\hline $6-11$ & 11 & 3 & \\
\hline $12-17$ & 36 & 5 & \\
\hline Racef & & & 0.69 \\
\hline White & 47 & 7 & \\
\hline Black & 4 & 1 & \\
\hline Asian/Pacific Islander & 2 & 1 & \\
\hline Hispanic ethnicity & & & 0.78 \\
\hline No & 47 & 8 & \\
\hline Yes & 8 & 1 & \\
\hline Period of diagnosis & & & 0.79 \\
\hline 1973-2000 & 28 & 5 & \\
\hline 2001-2008 & 27 & 4 & \\
\hline Received radiation $\ddagger$ & & & 0.25 \\
\hline No & 33 & 4 & \\
\hline Yes & 18 & 5 & \\
\hline Surgery type & & & 0.61 \\
\hline No resection & 20 & 3 & \\
\hline STR & 14 & 2 & \\
\hline GTR & 20 & 1 & \\
\hline \multicolumn{4}{|l|}{ Time to death in mos } \\
\hline Mean & & 30.4 & \\
\hline Median & & 15 & \\
\hline Range & & $0-98$ & \\
\hline
\end{tabular}

\section{Characteristics and Demographics}

Grade II ependymomas, including cellular, clear cell, tanycytic, papillary, and ependymoma NOS, are slowgrowing, indolent tumors. ${ }^{7,42}$ Our study found 5- and 10year OS to be $86 \%$ and $83 \%$, respectively, which is consistent with the reported literature. In a 2010 retrospective study using the Hirntumor (HIT) database ( $n=17$ Grade II ependymomas), Benesch et al. reported $100 \%$ OS and 94\% PFS after 4 years of follow-up. ${ }^{8}$ In a 2012 retrospective single-institution study ( $\mathrm{n}=11$ Grade II ependymomas), Stephen et al. reported 100\% PFS and OS after a mean of 51 months of follow-up. ${ }^{62}$ In a 2013 literature review of more than 30 series $(n=43$ Grade II ependymomas), Safaee et al. reported a 5-year OS of greater than $90 \%$ and a PFS of approximately $80 \% .^{59}$

This study found that females were much more likely to survive than males among pediatric subjects with Grade
TABLE 3. Multivariate analysis of risk factors for 10 -year mortality

\begin{tabular}{llcc}
\hline \multicolumn{1}{c}{ Variable } & $\mathrm{HR}$ & $95 \% \mathrm{Cl}$ & $\mathrm{p} \mathrm{Value}$ \\
\hline Sex & \multicolumn{3}{c}{} \\
\hline Male & 1.000 & Reference & \\
\hline Female & 0.151 & $0.024-0.940$ & $0.043^{*}$ \\
\hline Age at diagnosis & 0.892 & $0.737-1.080$ & 0.241 \\
\hline Year of diagnosis & & \\
\hline 1973-2000 & 1.000 & Reference & \\
\hline 2001-2008 & 5.615 & $0.853-36.969$ & 0.073 \\
\hline Received radiation† & & & \\
\hline No & 1.000 & Reference & \\
\hline Yes & 2.35805 & $0.486-11.440$ & 0.287 \\
\hline Extent of resection† & & & \\
\hline No resection & 1.000 & Reference & \\
\hline STR & 0.896 & $0.125-6.417$ & 0.913 \\
\hline GTR & 0.571 & $0.053-6.166$ & 0.645 \\
\hline
\end{tabular}

* Statistically significant.

$\dagger$ Unknowns are not shown.

II spinal ependymoma. To the best of our knowledge, such a finding in this neoplasm subgroup has not been previously reported. Published studies on this topic have not been powered for analysis stratified by grade. However, an association between male sex and mortality has been reported among intracranial ependymomas in adult populations ${ }^{45,57}$ Further prospective studies are warranted to elucidate the possible role of sex in the prognosis of pediatric spinal Grade II ependymoma. The data in our study are observational and cannot provide explanations for this sex-related disparity in survival outcomes. Our results are in keeping with reports in the literature. The higher incidence and worse outcomes of parenchymal CNS tumors in male versus female patients, independent of age, race, tumor histology (including gliomas, ependymomas, and medulloblastomas), and country of residence/origin, has been reported in the literature. . $30,35,37,46,52,58,63,70$ Sun et al., in a review examining this disparity, postulated that it may be due to sexually dimorphic biology, specifically sex chromosome-based mechanisms of growth regulation..$^{63}$ Male embryos are larger, contain more cells, and show differential expression of genes important for glucose metabolism (G6PD and HPRT1), cellular growth (XIAP), and gene regulation (DMNT3A and DMNT3B); these differences are evident at the blastocyst stage, before gonadal differentiation at 8 weeks. ${ }^{9,10,36,60,67}$ These differences are reported to have physiologically relevant manifestations; male embryos display increased glucose and pyruvate uptake and lactate production, while female embryos display greater $G 6 P D$ activity and increased activity through the pentose phosphate pathway. ${ }^{9,10,23,49}$ The Warburg effect describes the observation that tumor cells prefer anaerobic glycolysis as an energy source, and thus would be expected to have increased uptake of glucose and production of lactate. These metabolic differences may affect the probability, rate, or severity of oncogenic transformation in the CNS. Alternate explanations include sex-based differen- 
tial activation of the MAPK pathway, differential sensitivity to estradiol-mediated suppression of the MAPK pathway (correlating with differential rates of proliferation and apoptosis), and differential regulation of CREB, a growthregulating transcription factor. ${ }^{5,19,28,64,69}$ In an intracranial xenograft model of glioblastoma, estradiol induced tumor cell apoptosis and promoted survival. ${ }^{6}$ Although SEER data cannot provide further explanation for disparity in outcome based on sex, there is ongoing work reported in the literature to gain understanding of these differences.

This cohort had no significant association between age or race/ethnicity and outcomes in Grade II ependymoma. With regard to spinal ependymoma in general, Safaee et al. $(n=80)$ found a significant association between age and mortality, ${ }^{59}$ while Benesch et al. $(n=29)$ did not. ${ }^{8}$ However, neither paper provides outcome analysis stratified by tumor grade.

\section{Surgery and Adjuvant Radiation Therapy}

Maximally safe resection is the cornerstone of care in the management of pediatric Grade II spinal ependymomas. ${ }^{7,42,50}$ In this cohort, GTR was attained in $57 \%$ of subjects who underwent resection, which is on par with published accounts of 50\%-100\% in the pediatric literature..$^{8,59,62}$ Our study did not find a statistically significant relationship between extent of resection and OS; data on tumor progression were not available. Of note, among the 3 patients in our study who underwent resection and eventually died, the patient who achieved GTR survived 55 months, while the 2 patients with STR survived 8 and 13 months. While this small number is not amenable for statistical analysis, this finding is consistent with the widely reported connection between GTR and outcomes listed in the literature. An association between GTR and increased OS and PFS in cases of spinal ependymoma has been well documented in the adult literature and in a handful of pediatric studies; however, few studies provide analysis stratified by grade. ${ }^{11,12,14,16,17,59,62}$ Safaee et al. reported that among 43 Grade II ependymomas, GTR was associated with increased PFS. ${ }^{59}$ Benesch et al. $(n=29)$ did not find a statistically significant relationship between extent of resection and OS; however, they found that GTR trended toward an association with increased PFS $(\mathrm{p}=0.088) .{ }^{8}$

The role of adjuvant radiation therapy in the treatment of pediatric spinal ependymomas has historically been a subject of debate, as the rarity of these neoplasms has led to a paucity of data. Our study shows that in practice, about one-third of this cohort received radiation therapy, which is slightly lower than previously reported rates of $49 \%-58 \%$. 85,62 Our data also found that radiation therapy is statistically significantly more likely to be administered in conjunction with STR as opposed to GTR ( $p<0.001)$. Benesch et al. reported a similar pattern in their 2010 study; however, it did not reach statistical significance. ${ }^{8}$ This study did not find a significant relationship between radiation treatment and OS. It should be noted that, given the limited nature of the data regarding radiation therapy in SEER, it is difficult to draw conclusions regarding the impact of radiation therapy on outcomes in this study cohort. These findings are consistent with what has been published before in the literature. Safaee et al. ( $n=43$ Grade II ependymomas, total $\mathrm{n}=80$ ) found no significant association between radiotherapy and PFS in multivariate analyses pooling Grade I, II, and III spinal ependymoma. ${ }^{59}$ Lonjon et al. published a cohort $(n=17$ Grade II ependymomas, total $n=20)$ that achieved 90\% 10-year OS rates and 70\% 10-year PFS rates without the use of additional adjuvant radiation therapy. ${ }^{42}$ Neither study provided statistical analyses stratified by tumor grade. In the adult literature, the role of adjuvant radiation in the management of spinal ependymomas is also a matter of debate: some studies recommend postoperative radiation therapy in cases of STR but not GTR, ${ }^{18,40,41,65,66}$ others advocate for postoperative radiation therapy after $\mathrm{GTR},{ }^{38}$ and some maintain that radiation is not indicated regardless of degree of resection. ${ }^{20,26,42}$ Further studies are needed to determine the optimal management of these rare tumors.

\section{Limitations}

There are limitations to this study, many of which are related to the nature of the underlying data set. There is a lack of data about the focality, location, clinical symptoms, and functional status of the patients, which other studies have shown to be important prognostic indicators of outcome. ${ }^{54,59}$ The outcome available for examination is survival; there are no data about tumor progression or recurrence. This limits the ability to calculate PFS, which other studies have shown to be more influenced by treatment modalities than OS. ${ }^{8,59}$ There are no data regarding functional status preoperatively or postoperatively, which are highly clinically relevant. SEER does not contain information regarding the type, dose, field, timing, or duration of radiation therapy, rendering it difficult to derive conclusions about the impact of radiation treatment in this study cohort. There is also a lack of data on chemotherapeutic regimens in SEER; however, chemotherapy is not typically used in the treatment of Grade II spinal ependymomas. ${ }^{47,42,47,50}$ For each case, to what extent the "extent of resection" was coded based on operative reports/surgeon estimates versus postoperative imaging cannot be known from SEER. We do not have access to primary imaging data, and an independent comparison of pre- and postoperative scans to confirm the extent of resection was not possible. Likewise, while tumor histology is coded according to standardized methodology by coders with access to pathology reports, histological data were not available to us for independent verification and review. There are also no data about comorbid conditions that may have influenced the management or outcomes of the subjects in this cohort. The longitudinal nature of the database reflects the evolution of diagnostic and surgical care over the decades of observation. Changes in the histological classification criteria of Grade II spinal ependymomas over the time period examined in this study may lead to heterogeneity within the data. MRI was not developed until 1973, and mainstream incorporation of diagnostic MRI followed over the next 2 decades. This could result in heterogeneity within the "extent of resection" variable; specifically, it may be difficult to interpret "gross-total resection" in pre-MRI era patients, as they may have been classified as "subtotal resection" in the post-MRI era. Finally, as with all population-based studies, these data are observational in nature and cannot 
be used to deduce causality or to influence clinical decision making.

\section{Conclusions}

This study examined 64 cases of pediatric Grade II spinal ependymoma with a median of 9.2 years of follow-up and reported the demographic characteristics, treatment trends, and outcomes. Overall survival at 5 and 10 years was $86 \%$ and $83 \%$, respectively. Subjects were significantly more likely to undergo radiation therapy after STR than GTR. Female sex was associated with increased survival; other demographic factors, extent of resection, and radiation treatment were not.

\section{References}

1. Adams H, Avendaño J, Raza SM, Gokaslan ZL, Jallo GI, Quiñones-Hinojosa A: Prognostic factors and survival in primary malignant astrocytomas of the spinal cord: a population-based analysis from 1973 to 2007. Spine (Phila Pa 1976) 37:E727E735, 2012

2. Al-Halabi H, Montes JL, Atkinson J, Farmer JP, Freeman CR: Adjuvant radiotherapy in the treatment of pediatric myxopapillary ependymomas. Pediatr Blood Cancer 55:639-643, 2010

3. Arora RS, Alston RD, Eden TO, Estlin EJ, Moran A, Birch JM: Age-incidence patterns of primary CNS tumors in children, adolescents, and adults in England. Neuro Oncol 11:403-413, 2009

4. Balmaceda C: Chemotherapy for intramedullary spinal cord tumors. J Neurooncol 47:293-307, 2000

5. Barabás K, Szegõ EM, Kaszás A, Nagy GM, Juhász GD, Abrahám IM: Sex differences in oestrogen-induced p44/42 MAPK phosphorylation in the mouse brain in vivo. J Neuroendocrinol 18:621-628, 2006

6. Barone TA, Gorski JW, Greenberg SJ, Plunkett RJ: Estrogen increases survival in an orthotopic model of glioblastoma. $\mathbf{J}$ Neurooncol 95:37-48, 2009

7. Benesch M, Frappaz D, Massimino M: Spinal cord ependymomas in children and adolescents. Childs Nerv Syst 28:20172028, 2012

8. Benesch M, Weber-Mzell D, Gerber NU, von Hoff K, Deinlein F, Krauss J, et al: Ependymoma of the spinal cord in children and adolescents: a retrospective series from the HIT database. J Neurosurg Pediatr 6:137-144, 2010

9. Bermejo-Alvarez P, Rizos D, Lonergan P, Gutierrez-Adan A: Transcriptional sexual dimorphism during preimplantation embryo development and its consequences for developmental competence and adult health and disease. Reproduction 141:563-570, 2011

10. Bermejo-Alvarez P, Rizos D, Lonergan P, Gutierrez-Adan A: Transcriptional sexual dimorphism in elongating bovine embryos: implications for XCI and sex determination genes. Reproduction 141:801-808, 2011

11. Boström A, von Lehe M, Hartmann W, Pietsch T, Feuss M, Boström JP, et al: Surgery for spinal cord ependymomas: outcome and prognostic factors. Neurosurgery 68:302-309, 2011

12. Brotchi J, Dewitte O, Levivier M, Balériaux D, Vandesteene A, Raftopoulos C, et al: A survey of 65 tumors within the spinal cord: surgical results and the importance of preoperative magnetic resonance imaging. Neurosurgery 29:651-657, 1991

13. Chan HS, Becker LE, Hoffman HJ, Humphreys RP, Hendrick EB, Fitz CR, et al: Myxopapillary ependymoma of the filum terminale and cauda equina in childhood: report of seven cases and review of the literature. Neurosurgery 14:204-210, 1984

14. Chao ST, Kobayashi T, Benzel E, Reddy CA, Stevens GH, Prayson RA, et al: The role of adjuvant radiation therapy in the treatment of spinal myxopapillary ependymomas. J Neurosurg Spine 14:59-64, 2011
15. Clark TG, Bradburn MJ, Love SB, Altman DG: Survival analysis part I: basic concepts and first analyses. Br J Cancer 89:232-238, 2003

16. Cooper PR: Outcome after operative treatment of intramedullary spinal cord tumors in adults: intermediate and long-term results in 51 patients. Neurosurgery 25:855-859, 1989

17. Cristante L, Herrmann HD: Surgical management of intramedullary spinal cord tumors: functional outcome and sources of morbidity. Neurosurgery 35:69-76, 1994

18. Di Marco A, Griso C, Pradella R, Campostrini F, Garusi GF: Postoperative management of primary spinal cord ependymomas. Acta Oncol 27:371-375, 1988

19. Ehrlichman LK, Ford JW, Roelofs KJ, Tedeschi-Filho W, Futchko JS, Ramacciotti E, et al: Gender-dependent differential phosphorylation in the ERK signaling pathway is associated with increased MMP2 activity in rat aortic smooth muscle cells. J Surg Res 160:18-24, 2010

20. Ellenbogen RG, Abdulrauf SI, Sekhar LN: Principles of Neurological Surgery, ed 3. Philadelphia: Saunders Elsevier, 2012

21. Epstein FJ, Farmer JP, Freed D: Adult intramedullary spinal cord ependymomas: the result of surgery in 38 patients. J Neurosurg 79:204-209, 1993

22. Fassett DR, Pingree J, Kestle JR: The high incidence of tumor dissemination in myxopapillary ependymoma in pediatric patients. Report of five cases and review of the literature. J Neurosurg 102 (1 Suppl):59-64, 2005

23. Gardner DK, Larman MG, Thouas GA: Sex-related physiology of the preimplantation embryo. Mol Hum Reprod 16:539547, 2010

24. Garrett PG, Simpson WJ: Ependymomas: results of radiation treatment. Int J Radiat Oncol Biol Phys 9:1121-1124, 1983

25. Garrido E, Stein BM: Microsurgical removal of intramedullary spinal cord tumors. Surg Neurol 7:215-219, 1977

26. Goh KY, Velasquez L, Epstein FJ: Pediatric intramedullary spinal cord tumors: is surgery alone enough? Pediatr Neurosurg 27:34-39, 1997

27. Gomez DR, Missett BT, Wara WM, Lamborn KR, Prados MD, Chang S, et al: High failure rate in spinal ependymomas with long-term follow-up. Neuro Oncol 7:254-259, 2005

28. Gresack JE, Schafe GE, Orr PT, Frick KM: Sex differences in contextual fear conditioning are associated with differential ventral hippocampal extracellular signal-regulated kinase activation. Neuroscience 159:451-467, 2009

29. Hayden Gephart MG, Lober RM, Arrigo RT, Zygourakis CC, Guzman R, Boakye M, et al: Trends in the diagnosis and treatment of pediatric primary spinal cord tumors. J Neurosurg Pediatr 10:555-559, 2012

30. Hess KR, Broglio KR, Bondy ML: Adult glioma incidence trends in the United States, 1977-2000. Cancer 101:22932299, 2004

31. Houten JK, Weiner HL: Pediatric intramedullary spinal cord tumors: special considerations. J Neurooncol 47:225-230, 2000

32. Hsu S, Quattrone M, Ostrom Q, Ryken TC, Sloan AE, Barnholtz-Sloan JS: Incidence patterns for primary malignant spinal cord gliomas: a Surveillance, Epidemiology, and End Results study. J Neurosurg Spine 14:742-747, 2011

33. Huisman TA: Pediatric tumors of the spine. Cancer Imaging 9 (Spec No A):S45-48, 2009

34. Jallo GI, Kim BS, Epstein F: The current management of intramedullary neoplasms in children and young adults. Ann Neurosurg 1:1-13, 2001

35. Karkouri M, Zafad S, Khattab M, Benjaafar N, El Kacemi H, Sefiani S, et al: Epidemiologic profile of pediatric brain tumors in Morocco. Childs Nerv Syst 26:1021-1027, 2010

36. Kobayashi S, Isotani A, Mise N, Yamamoto M, Fujihara Y, Kaseda K, et al: Comparison of gene expression in male and female mouse blastocysts revealed imprinting of the X-linked 
gene, Rhox 5/Pem, at preimplantation stages. Curr Biol 16:166-172, 2006

37. Kohler BA, Ward E, McCarthy BJ, Schymura MJ, Ries LA, Eheman C, et al: Annual report to the nation on the status of cancer, 1975-2007, featuring tumors of the brain and other nervous system. J Natl Cancer Inst 103:714-736, 2011

38. Kopelson G, Linggood RM, Kleinman GM, Doucette J, Wang CC: Management of intramedullary spinal cord tumors. Radiology 135:473-479, 1980

39. Lam S, Lin Y, Melkonian S: Analysis of risk factors and survival in pediatric high-grade spinal cord astrocytoma: a population-based study. Pediatr Neurosurg 48:299-305, 2012

40. Lee TT, Gromelski EB, Green BA: Surgical treatment of spinal ependymoma and post-operative radiotherapy. Acta Neurochir (Wien) 140:309-313, 1998

41. Lin YH, Huang CI, Wong TT, Chen MH, Shiau CY, Wang LW, et al: Treatment of spinal cord ependymomas by surgery with or without postoperative radiotherapy. J Neurooncol 71:205210,2005

42. Lonjon M, Goh KY, Epstein FJ: Intramedullary spinal cord ependymomas in children: treatment, results and follow-up. Pediatr Neurosurg 29:178-183, 1998

43. Louis DN, Ohgaki H, Wiestler OD, Cavenee WK, Burger PC, Jouvet A, et al: The 2007 WHO classification of tumours of the central nervous system. Acta Neuropathol 114:97-109, 2007

44. McGuire CS, Sainani KL, Fisher PG: Incidence patterns for ependymoma: a surveillance, epidemiology, and end results study. J Neurosurg 110:725-729, 2009

45. McLaughlin MP, Marcus RB Jr, Buatti JM, McCollough WM, Mickle JP, Kedar A, et al: Ependymoma: results, prognostic factors and treatment recommendations. Int J Radiat Oncol Biol Phys 40:845-850, 1998

46. Mehrazin M, Rahmat H, Yavari P: Epidemiology of primary intracranial tumors in Iran, 1978-2003. Asian Pac J Cancer Prev 7:283-288, 2006

47. Merchant TE, Kiehna EN, Thompson SJ, Heideman R, Sanford RA, Kun LE: Pediatric low-grade and ependymal spinal cord tumors. Pediatr Neurosurg 32:30-36, 2000

48. Milano MT, Johnson MD, Sul J, Mohile NA, Korones DN, Okunieff P, et al: Primary spinal cord glioma: a Surveillance, Epidemiology, and End Results database study. J Neurooncol 98:83-92, 2010

49. Mittwoch U: The elusive action of sex-determining genes: mitochondria to the rescue? J Theor Biol 228:359-365, 2004

50. Nadkarni TD, Rekate HL: Pediatric intramedullary spinal cord tumors. Critical review of the literature. Childs Nerv Syst 15:17-28, 1999

51. Nagasawa DT, Smith ZA, Cremer N, Fong C, Lu DC, Yang I: Complications associated with the treatment for spinal ependymomas. Neurosurg Focus 31(4):E13, 2011

52. Nomura E, Ioka A, Tsukuma $\mathrm{H}$ : Trends in the incidence of primary intracranial tumors in Osaka, Japan. Jpn J Clin Oncol 41:291-294, 2011

53. O'Sullivan C, Jenkin RD, Doherty MA, Hoffman HJ, Greenberg ML: Spinal cord tumors in children: long-term results of combined surgical and radiation treatment. J Neurosurg 81:507-512, 1994

54. Oh MC, Sayegh ET, Safaee M, Sun MZ, Kaur G, Kim JM, et al: Prognosis by tumor location for pediatric spinal cord ependymomas. J Neurosurg Pediatr 11:282-288, 2013

55. Phillips JS, Stewart AK (eds): FORDS: Facility Oncology Revised Data Standards, Revised for 2004. Chicago: American College of Surgeons, 2002 (https://www.facs.org/ /media/ files/quality\%20programs/cancer/coc/fords/fordsrevised0904. ashx) [Accessed October 26, 2014]

56. Pica A, Miller R, Villà S, Kadish SP, Anacak Y, Abusaris H, et al: The results of surgery, with or without radiotherapy, for primary spinal myxopapillary ependymoma: a retrospective study from the rare cancer network. Int J Radiat Oncol Biol Phys 74:1114-1120, 2009

57. Reni M, Gatta G, Mazza E, Vecht C: Ependymoma. Crit Rev Oncol Hematol 63:81-89, 2007

58. Rigau V, Zouaoui S, Mathieu-Daudé H, Darlix A, Maran A, Trétarre B, et al: French brain tumor database: 5-year histological results on 25756 cases. Brain Pathol 21:633-644, 2011

59. Safaee M, Oh MC, Kim JM, Aranda D, Tarapore PE, Cage TA, et al: Histologic grade and extent of resection are associated with survival in pediatric spinal cord ependymomas. Childs Nerv Syst 29:2057-2064, 2013

60. Sánchez FJ, Vilain E: Genes and brain sex differences. Prog Brain Res 186:65-76, 2010

61. Schellinger KA, Propp JM, Villano JL, McCarthy BJ: Descriptive epidemiology of primary spinal cord tumors. J Neurooncol 87:173-179, 2008

62. Stephen JH, Sievert AJ, Madsen PJ, Judkins AR, Resnick AC, Storm PB, et al: Spinal cord ependymomas and myxopapillary ependymomas in the first 2 decades of life: a clinicopathological and immunohistochemical characterization of 19 cases. J Neurosurg Pediatr 9:646-653, 2012

63. Sun T, Warrington NM, Rubin JB: Why does Jack, and not Jill, break his crown? Sex disparity in brain tumors. Biol Sex Differ 3:3, 2012

64. Tatevossian RG, Lawson AR, Forshew T, Hindley GF, Ellison DW, Sheer D: MAPK pathway activation and the origins of pediatric low-grade astrocytomas. J Cell Physiol 222:509-514, 2010

65. Wahab SH, Simpson JR, Michalski JM, Mansur DB: Long term outcome with post-operative radiation therapy for spinal canal ependymoma. J Neurooncol 83:85-89, 2007

66. Whitaker SJ, Bessell EM, Ashley SE, Bloom HJ, Bell BA, Brada M: Postoperative radiotherapy in the management of spinal cord ependymoma. J Neurosurg 74:720-728, 1991

67. Wilson CA, Davies DC: The control of sexual differentiation of the reproductive system and brain. Reproduction 133:331359,2007

68. Wong AP, Dahdaleh NS, Fessler RG, Melkonian SC, Lin Y, Smith ZA, et al: Risk factors and long-term survival in adult patients with primary malignant spinal cord astrocytomas. J Neurooncol 115:493-503, 2013

69. Zhang L, Li Bs, Zhao W, Chang YH, Ma W, Dragan M, et al: Sex-related differences in MAPKs activation in rat astrocytes: effects of estrogen on cell death. Brain Res Mol Brain Res 103:1-11, 2002

70. Zhou D, Zhang Y, Liu H, Luo S, Luo L, Dai K: Epidemiology of nervous system tumors in children: a survey of 1,485 cases in Beijing Tiantan Hospital from 2001 to 2005. Pediatr Neurosurg 44:97-103, 2008

\section{Author Contributions}

Conception and design: Lam. Acquisition of data: Lam, Melkonian. Analysis and interpretation of data: Lam, Lin, Melkonian. Drafting the article: Lin. Critically revising the article: all authors. Reviewed submitted version of manuscript: all authors. Approved the final version of the manuscript on behalf of all authors: Lam. Statistical analysis: Lin, Melkonian. Administrative/technical/material support: Lam, Jea. Study supervision: Lam.

\section{Correspondence}

Sandi Lam, Department of Neurosurgery, Baylor College of Medicine, Texas Children's Hospital, 6701 Fannin St., Ste. 1230, Houston, TX 77030. email: sklam@texaschildrens.org. 